STUDI

FRANCESI

\section{Studi Francesi}

Rivista quadrimestrale fondata da Franco Simone

190 (LXIV | I) | 2020

Varia - fasc. I - gennaio-aprile 2020

\title{
THÉOPHILE GAUTIER, CEuvres complètes. Romans, contes et nouvelles, tome 7, Contes et nouvelles, 2
}

\section{Lise Sabourin}

\section{OpenEdition}

\section{Journals}

\section{Édition électronique}

URL : https://journals.openedition.org/studifrancesi/22996

DOI : 10.4000/studifrancesi.22996

ISSN : 2421-5856

Éditeur

Rosenberg \& Sellier

\section{Édition imprimée}

Date de publication : 1 avril 2020

Pagination : 201-202

ISSN : 0039-2944

\section{Référence électronique}

Lise Sabourin, « THÉOPHILE GAUTIER, E Euvres complètes. Romans, contes et nouvelles, tome 7, Contes et nouvelles, 2 », Studi Francesi [En ligne], 190 (LXIV | I) | 2020, mis en ligne le 01 mai 2020, consulté le 03 août 2021. URL : http://journals.openedition.org/studifrancesi/22996 ; DOI : https://doi.org/10.4000/ studifrancesi.22996

Ce document a été généré automatiquement le 3 août 2021

\section{(c) $($ ) $(9)$}

Studi Francesi è distribuita con Licenza Creative Commons Attribuzione - Non commerciale - Non opere derivate 4.0 Internazionale. 


\title{
THÉOPHILE GAUTIER, CEuvres complètes. Romans, contes et nouvelles, tome 7 , Contes et nouvelles, 2
}

\author{
Lise Sabourin
}

\section{RÉFÉRENCE}

THÉOPHILE GAUTIER, CEuvres complètes. Romans, contes et nouvelles, tome 7, Contes et nouvelles, 2, textes établis, présentés et annotés par A. Montandon, A. Geisler-Szmulewicz, F. Brunet, P. Tortonese, É. Stead, V. Bui, M. Lavaud, Paris, Champion, 2018, 856 pp.

1 Poursuivant l'édition chronologique des contes et nouvelles de Gautier, ce second tome contient des œuvres parues de 1837 à 1866, alternant des récits assez accessoires avec quelques-uns de ses chefs-d'œuvre les plus reconnus.

Une Nuit de Cléopâtre (pp. 7-51), présentée par François BRUNET (pp. 7-12), résulte d'un projet avorté de livret de ballet pour Marie Taglioni en 1837. Nourri de La Tour de Nesle dumasienne comme des Lettres écrites d'Égypte et de Nubie par Champollion, Gautier imagine les amours de la rusée Cléopâtre comme une «nouvelle chorégraphie» sur fond de visites au Louvre et de consultations des planches de la Description de l'Égypte.

La Toison d'or (pp.53-111), introduite par Alain MONTANDON (pp.53-60), au contraire propose une blonde héroïne, après le voyage en Belgique de 1836 et la contemplation de Rubens à la cathédrale d'Anvers: cette Gretchen goethéenne a pourtant les yeux noirs de la byronienne Haydée.

4 L'Âme de la maison (pp. 113-143), présentée par François BRUNET (pp. 113-118), est une «aimable bluette» de 1839, écrite sur une base prêtée à Richter par Nerval, et constitue une sorte de réécriture du Bonheur à la maison de 1831: merveilleux et poésie du quotidien marquent cette idylle tragique. 
5 Le Chevalier double (pp. 145-163), introduite par Paolo TORTONESE (pp. 145-152), présente en 1840 le motif du dédoublement moral d'origine diabolique cher à Gautier, qui s'inspire en l'occurrence de contes scandinaves (après Ampère et Marmier), de chants danois de Heine et de récits traditionnels sur la femme-cygne et l'homme-corbeau.

$6 \quad$ Le Pied de momie (pp. 165-183), présenté par Alain MONTANDON (pp. 165-169), également de 1840 , passe du réalisme au fantastique, sur le thème du jeune homme amoureux d'une belle morte promis à tant de développements chez l'auteur: le dandy désinvolte pour le moment exerce sa fantaisie fétichiste grâce aux détails donnés par Vivant Denon sur la tombe de Ramsès III dans son Voyage dans la Basse et la Haute Égypte.

7 Deux acteurs pour un rôle (pp. 185-199), introduit par Alain MONTANDON (pp. 185-188), s'inspire des Amours de Vienne de Nerval, entre Katy et Heinrich, double ténébreux du Robert le diable de Meyerbeer.

8 La Mille et deuxième nuit (pp. 201-251), présentée par Évanghélia STEAD (pp. 201-224), méconnue exotique, a souvent déplu par sa fin tragique puisque cette arabesque à structure gigogne abolit la puissance créatrice de Sheherazade.

9 Une Visite nocturne (pp. 253-261), introduite par Alain MONTANDON (pp. 253-255), recourt de nouveau à Nerval pour satisfaire à une demande de Karr pour Les Guêpes par un rêve lunaire.

10 Le Berger (pp. 263-285), présenté par François BRUNET (pp. 263-265), est un conte inspiré d'une histoire rapportée par Vasari sur le don qui permit à un jeune homme doué pour le paysage de devenir célèbre en peignant sur le motif comme le pratiquait l'école de Barbizon en 1844.

11 Le Roi Candaule (pp. 287-393), introduit par Anne GEISLER-SZMULEWICZ (pp. 287-332), sur sources empruntées à Hérodote, Platon et Pline, explore avec humour l'érotisme païen cher à Gautier, mais aussi le motif de la femme fatale prise entre deux hommes.

12 Feuillets de l'album d'un jeune rapin (pp. 395-427), présentés par Anne GEISLER-SZMULEWICZ (pp. 395-409), est une œuvre quasi ignorée, alors qu'elle traite du motif bien personnel à Gautier de l'apprentissage artistique, malgré l'incompréhension publique, du peintre porté par son individualité créatrice, dût-elle le laisser sans gloire.

13 L'Oreiller d'une jeune fille (pp. 429-441), introduit par Alain MONTANDON (pp. 429-431), est également paru avec vignettes, dans un keepsake à tonalité religieuse de 1845, plus rare chez cet auteur.

14 Le Club des Hachichins (pp. 443-471), présenté par Alain MONTANDON (pp. 443-444), relate quelques expériences de drogue vécus par Gautier en 1843-1845, retraçant la fantasia visuelle et sensitive d'une extase qu'il préféra vite arrêter pour reprendre la maîtrise de ses motifs hoffmanniens.

15 Le Pavillon sur l'eau (pp. 473-509), introduit par Véronique BUI (pp. 473-489), montre bien tout l'intérêt de Gautier pour la Chine, en l'occurrence nourri de contes traduits par Rémusat, mais aussi de son rêve de voyage transmis par la Société asiatique.

16 L'Enfant aux souliers de pain (pp. 511-523), présenté par Alain MONTANDON (pp. 511-514), reprend une légende bohémienne rapportée par Grimm à laquelle en 1849 Gautier donne une tournure esthétique pour un public d'enfants.

17 Arria Marcella (pp. 525-583), introduite par François BRUNET (pp. 525-537), émerge évidemment du lot, typique des années mystiques de 1852-1856, après le voyage en Italie de 1850 qui permit à Gautier de rêver sur l'empreinte sensuelle d'une Pompéienne 
conservée au musée de Naples que l'amour fait ressurgir comme dans Le Roman de la momie.

18 Avatar (pp. 585-683), présenté par François BRUNET (pp. 585-590), autre moment fort de cette période fantastique, n'oublie pas l'humour sur fond d'angoisse existentielle, avec son trio d'amants sous la baguette du redoutable échangeur d'âmes: autre preuve de l'ouverture indianiste de Gautier, aussi bien quand il lit la traduction de Sacountala que quand il voit les bayadères danser à Paris ou l'exposition exotique du Crystal Palace.

19 Jettatura (pp. 685-777), introduit par François BRUNET (pp. 685-691), reprend en 1856 un souvenir napolitain, cumulant pour cette tragédie fataliste l'ambiguïté rationaliste et la transposition pittoresque des superstitions méditerranéennes.

20 Mademoiselle Dafné (pp. 779-843), présentée par Martine LAVAUd (pp. 779-801), de 1866, donne une tonalité assez grotesque au motif de la courtisane corrompue tout en libérant l'imaginaire piranésien des souterrains romains. 